\title{
Polypropylene Blends with m-EPR Copolymers: Mechanical and Rheological Properties
}

\section{Iztok Švab, ${ }^{1, *}$ Anđela Pustak, ${ }^{2,}{ }^{\star}$ Matjaž Denac, ${ }^{3}$ Andrijana Sever Škapin, ${ }^{4}$ Mirela Leskovac, ${ }^{5}$ Vojko Musil ${ }^{3,6}$ and Ivan Šmit ${ }^{2}$}

\author{
${ }^{1}$ ISOKON, Production and Processing of Thermoplastics, Ltd, Mestni trg 5a, 3210 Slovenske Konjice, Slovenia \\ ${ }^{2}$ Ruđer Bošković Institute, Division of Materials Chemistry, Bijenička 54, 10002 Zagreb, Croatia \\ ${ }^{3}$ University of Maribor, FEB Maribor, Institute of Technology, Razlagova 14, 2000 Maribor, Slovenia \\ ${ }^{4}$ Slovenian National Building and Civil Engineering Institute, Department of Materials, Laboratory for polymers, \\ Dimičeva 12, 1000 Ljubljana, Slovenia \\ ${ }^{5}$ University of Zagreb, Faculty of Chemical Engineering and Technology, Savska 16, 10000 Zagreb, Croatia \\ ${ }^{6}$ Faculty of polymer technology, Ozare 19, 2380 Slovenj Gradec, Slovenia \\ *Corresponding author: E-mail: Iztok.Svab@isokon.si \\ phone: ++386(0)3757 11 37; fax: ++386(0)3757 1063 \\ apustak@irb.hr \\ phone: ++ 38514571255
}

Received: 22-11-2017

\begin{abstract}
The effects of two metallocene ethylene-propylene-based elastomers (m-EPR1 and m-EPR2) differing in molecular mass and viscosity on mechanical, rheological and interfacial properties were compared. The $\mathrm{m}$-EPR elastomers were added to iPP in $2.5,5,10,15$, and 20 vol.\%. Torque values, elongation at break and impact strength measured of the iPP/m-EPR1 blends were higher than the iPP/m-EPR2 blends due to higher molten viscosity of m-EPR1 than m-EPR2 copolymer. Slight differences in Young moduli as well as in tensile strength at yield and at break might indicate that tensile properties of iPP/m-EPR blends were not significantly affected by difference in viscosity or molecular mass, miscibility and spherulite size. Optimization diagrams indicated the metallocene m-EPR copolymers are efficient impact modifiers for polypropylene and showed good balancing of mechanical properties in iPP/m-EPR blends.
\end{abstract}

Keywords: Isotactic polypropylene; metallocene ethylene-propylene-based elastomers; blends; mechanical properties; adhesion parameters

\section{Introduction}

The addition of different types of specially designed elastomers to isotactic polypropylene is the common way to increase the toughness and to improve impact properties of the polypropylene. The blending of the semi-crystalline isotactic polypropylene by melt mixing with different elastomeric rubbers have been studied for three decades now..$^{1-12}$ The most frequent used elastomers in modification of istotactic polyproylene are ethylene propylene diene monomer $(\mathrm{EPDM}){ }^{2-3}$ ethylene-propylene rubber (EPR), ${ }^{4,5,6,7}$ styrene-butadiene-styrene triblock copolymer (SBS), ${ }^{8,9}$ or styrene-ethylene/butylene-styrene triblock copolymer (SEBS) ${ }^{9,10}$ and elastomer PEOC, copolymer of ethylene and octene (PEOC). ${ }^{11}$ The prior role of this elastomers is to modify/improve the impact properties of polyolefins and to achieve certain level of compatibility (e.g. partial miscibillity or co-crystabillity if possible) with polymeric matrix to additionally improve other properties as well.

The investigation of polypropylene-based copolymers or ethylene-propylene elastomers with polyolefins, was mostly oriented on achieving better optimization of mechanical properties and consequently other properties as well. 
Zhang and coworkers studied the influence of copolymerization on structure and mechanical properties of iPP/EPR random copolymer in situ blends. The investigation showed that the mechanical properties of the blends, including the impact strength and flexural modulus, depended on copolymerization conditions. The impact strength was influenced also by the amount of random copolymer. ${ }^{12}$

Nitta et al. investigated the mechanical properties for the binary blends of isotactic polypropylene (iPP) and random copolymers of ethylene-propylene (EP). ${ }^{13}$ The iPP/ EP blends were partly miscible in the melt. The addition of the novel EP copolymers played an important role in the modification of mechanical properties of iPP and final morphology. ${ }^{13}$ Grain et al. studied the influence of the molecular weight of dispersed phase in ethylene-propylene rubber in modified isotactic polypropylene (iPP/EPR) blend. ${ }^{14}$ The ductile-brittle transitions did not correlate linearly with $\mathrm{M}_{w}$, suggesting the macroscopic behavior of the blend is controlled by the morphology of the EPR particles. Dynamical mechanical analysis (DMA) showed relationship between molecule relaxation processes and mechanical properties. Similar investigation was done by Oracio and coworkes ${ }^{15}$ who studied the rubber molecular relaxations with DMA and obtained information about mechanical characteristics and the deformation mechamisms for the investigated iPP/EPR materials. ${ }^{15}$ Oracio and coworkes showed that the iPP phase is more effective in stiffening the matrix and provide better tensile elastic behaviour than EPR based materials. ${ }^{15}$

An iPP/EPR blend in-situ synthesized by spherical Ziegler-Natta catalyst has also been investigated by the same investigation group. ${ }^{16}$ The synergistic effect between random copolymer and copolymer has been found to be the key factor for high impact strength at low temperature. The thermal study clearly shows that, polyethylene PE segments of different lengths in the segmented copolymer fractions can form crystalline lamellae of different thickness. ${ }^{16}$

The influence of the nucleation (agents) of ethylenepropylene rubber modified isotactic polypropylene on ductile-brittle transition of iPP/EPR blends was studies by Grein and coworker and have found positive effects on mechanical properties. ${ }^{17}$

Trongtorsak and coworkers also reported improvement of mechanical properties of $\mathrm{iPP} / \mathrm{m}$-EPR blends with the addition of calcium stearate as $\beta$-nucleation agent, especially the improvement of notched Izod and strength. ${ }^{18}$

Thereby, metallocene EPR copolymers (m-EPR) with propylene being the major component ( $>80 \mathrm{wt} \%$ according to producer) were applied as impact modifiers for polypropylene in our investigation. Two chosen Vista$\operatorname{maxx}^{\mathrm{TM}}$ thermoplastic elastomers, signed as $\mathrm{m}$-EPR1 and $\mathrm{m}$-EPR2, are actually specialty co/terpolymers of propylene balanced with ethylene and other $\alpha$-olefins with different viscosity (e.g. different molecular mass) and compatible with various polyolefins in different extent. ${ }^{19,20}$

The goal was to study the mechanical properties of $\mathrm{iPP} / \mathrm{m}$-EPR blends and to compare the experimental and calculated results using some custom models for mechanical properties. Comprehensive study of interaction in iP$\mathrm{P} / \mathrm{m}$-EPR blends with different content of elastomer was also preformed to estimate the influence of interactivity and possible miscibility of $\mathrm{m}$-EPR elastomers with isotactic polypropylene primarly on mechanical properties.

\section{Experimental Part}

\section{1. Materials}

Isotactic polypropylene (trade name Moplen) used as polymer matrix was supplied by LyondellBasell, Netherlands. Two metallocene propylene-ethylene copolymers with different viscosity are used from Exxon Mobil producer. ${ }^{19,20}$ The properties of used polymers and fillers are listed in Table 1.

\section{2. Sample Preparation}

Binary iPP/m-EPR blends were prepared in a Brabender Plasti-Corder kneading chamber. The content of m-EPR copolymers in blends was 2.5, 5, 10, 15 and 20 vol.\%. The components were kneaded for $7 \mathrm{~min}$, in a chamber preheated to $200{ }^{\circ} \mathrm{C}$, with a rotor speed of 50 $\mathrm{min}^{-1}$. After kneading, the melt was rapidly transferred to a preheated laboratory press and compression moulded into 1- and 4-mm thick plates. The pressing temperature was $220^{\circ} \mathrm{C}$, the pressure 100 bar and the pressing time 14 min for $1-\mathrm{mm}$, and $11.5 \mathrm{~min}$ for $4-\mathrm{mm}$ thick plates. The plates were used for specimen preparation for morphology observation and mechanical testing.

Table 1. The properties of used materials

\begin{tabular}{llcccc}
\hline Polymer & \multicolumn{1}{c}{$\begin{array}{c}\text { Commercial } \\
\text { name }\end{array}$} & $\begin{array}{c}\text { Density } \\
\left(\mathbf{g ~ c m}^{-\mathbf{3}}\right)\end{array}$ & $\begin{array}{c}\mathbf{M F I} \\
\left(\mathbf{g ~ \mathbf { ~ 1 0 }} \mathbf{~ m i n}^{-\mathbf{1}}\right)\end{array}$ & $\begin{array}{c}\mathbf{M}_{\mathbf{n}} \\
\left(\mathbf{g} \mathbf{~ m o l}^{-\mathbf{1}}\right)\end{array}$ & $\mathbf{M}_{\mathbf{w}} / \mathbf{M}_{\mathbf{n}}$ \\
\hline iPP & Moplen HP501L & 0.90 & $6.0^{\mathrm{a}}$ & $120.000^{\mathrm{c}}$ & 5.40 \\
m-EPR1 & Vistamaxx-VM-1100 & 0.863 & $4.5^{\mathrm{b}}$ & $92.900^{\mathrm{c}}$ & 3.40 \\
m-EPR2 & Vistamaxx-VM-1120 & 0.863 & 20 & $48.100^{\mathrm{c}}$ & 2.66 \\
\hline
\end{tabular}

a) according to ISO $1133\left(230^{\circ} \mathrm{C} / 2.16 \mathrm{~kg}\right)$ b) according to ISO $1133\left(200^{\circ} \mathrm{C} / 5 \mathrm{~kg}\right)$ c) measured with exclusion chromatography with PS standard

Švab et al.: Polypropylene Blends with m-EPR Copolymers: ... 


\section{3. Testing Methods}

\section{3. 1. Steady State Torque $\left(\tau_{M}\right)$}

The torque value $\left(\tau_{\mathrm{M}}\right)$ of iPP/m-EPR blends was determined from the diagram of kneading in the Brabender kneading chamber. The average $\boldsymbol{\tau}_{\mathrm{M}}$ value was calculated on the basis of 5 measurements carried out for each sample with the same filling volume.

\section{3. 2. Tensile Tests}

Tensile properties of iPP/m-EPR blends (Young's modulus, yield stress and strain, tensile strength at break, elongation at break) were measured according to ISO 527 standard using Zwick 147,670 Z100/SN5A apparatus at 23 ${ }^{\circ} \mathrm{C}$ and strain rate of $2 \mathrm{~mm} / \mathrm{min}$. For each sample, 5 measurements were carried out.

\section{3. 3. Notched Impact Strength}

Notched impact strength of iPP/m-EPR blends was measured by Zwick apparatus at $25^{\circ} \mathrm{C}$ according to Charpy test (DIN 53453). For each sample, 12 measurements were carried out.

\section{3. 4. Contact Angle Measurement}

Surface free energies of used polymers, as well as their corresponding dispersive and polar components, were determined by measuring contact angle. Contact angles of the isotactic polypropylene and propylene-ethylene copolymers were measured on a contact angle goniometer DataPhysics OCA 20 Instrument at temperature of $23^{\circ} \mathrm{C}$. Sessile drops $(2 \mu \mathrm{L})$ of test liquids: water (distilled twice $\lambda=1.33 \mu \mathrm{Lcm}^{-1}$ ), formamide (p.a. 99.5\%, Fluka) and diiodomethane (p.a. 99\%, Aldrich) were used for the advancing contact angle measurements at $23{ }^{\circ} \mathrm{C}$. The surface tensions of the test liquids used for contact angle measurements are presented in Table 2. The average values of at least five drops at different places of the same sample were taken and the standard deviation was always less than $2 \%$.

Surface free energies of the iPP and elastomers $\left(\gamma_{1}\right)$ were calculated using harmonic mean equation according to Wu's model presented with equation (1): ${ }^{21}$

$$
\gamma_{l}(1+\cos \theta)=\frac{4 \gamma_{s}^{d} \gamma_{l}^{d}}{\gamma_{s}^{d}+\gamma_{l}^{d}}+\frac{4 \gamma_{s}^{p} \gamma_{l}^{p}}{\gamma_{s}^{p}+\gamma_{l}^{p}}
$$

where $\gamma^{\mathrm{p}}$ was the dispersive and $\gamma^{\mathrm{d}}$ the polar component of the surface free energy (surface tension), $\gamma_{1}$ and $\gamma_{s}$ were the surface tension of liquid and surface free energy of solid, respectively.

Surface free energies of the iPP and elastomers were presented in Table 4 . The interfacial free energy, $\gamma_{\mathrm{AB}}$, work
Table 2. Surface free energy $(\gamma)$, dispersion $\left(\gamma^{d}\right)$ and polar components $\left(\gamma^{p}\right)$ of surface free energy of test liquids used for contact angle measurements

\begin{tabular}{lccc}
\hline Test liquids & $\gamma\left(\mathbf{m} \mathbf{J m}^{-\mathbf{2}}\right)$ & $\gamma^{d}\left(\mathbf{m J m}^{-\mathbf{2}}\right)$ & $\gamma^{p}\left(\mathbf{m} \mathbf{J m}^{-\mathbf{2}}\right)$ \\
\hline Water & 72.8 & 21.8 & 51.0 \\
Formamide & 58.0 & 39.0 & 19.0 \\
Diiodomethane & 50.8 & 50.8 & 0.0 \\
\hline
\end{tabular}

of adhesion, $W_{\mathrm{AB}}$, and spreading coefficient, $S_{\mathrm{AB}}$, of all polymer/elastomer blend pairs were calculated from obtained $\gamma$ values using equations (2-4) and presented in Table 5:

$$
\begin{aligned}
& \gamma_{A B}=\gamma_{A}+\gamma_{B}-\frac{4 \gamma_{A}^{d} \gamma_{B}^{d}}{\gamma_{A}^{d}+\gamma_{B}^{d}}+\frac{4 \gamma_{A}^{p} \gamma_{B}^{p}}{\gamma_{A}^{p}+\gamma_{B}^{p}} \\
& W_{A B}=\gamma_{A}+\gamma_{B}-\gamma_{A B} \\
& S_{A B}=\gamma_{B}-\gamma_{A}-\gamma_{A B}
\end{aligned}
$$

where subscripts $A$ and $B$ correspond to the phases in blends (A-matrix, B- elastomer) and superscripts $d$ and $p$ mean dispersed and polar components of interfacial free energy $\gamma$. The results from Table 4 and Table 5 are presented in Adhesion parameters of $i P P / m-E P R$ blends section.

\section{Results and Discussion 3. 1. The Mixing Torque Values of the iPP/m-EPR Blends}

The mixing torque values $\left(\tau_{\mathrm{M}}\right)$ provide information how toughening elastomeric $\mathrm{m}$-EPR modifier affect processabillity of the iPP/m-EPR blends. The torque values can be considered as a measure of the viscosity under the same mixing conditions, including the same filling volume. The torque $\tau_{\mathrm{M}}$ increases by adding components in batch mixer and decreases after the polypropylene melting and reaches constant value around sixth minute of mixing ( $\tau_{M}$ values in Figure 1 are measured at $7^{\text {th }} \mathrm{min}$ ) due to process of homogenization and equalized viscosity of blends. ${ }^{22}$

The $\tau_{\mathrm{M}}$ values of two blend systems begun to diverge already at minimal addition of m-EPR's (2.5 vol.\% showed in Figure 1): the blends with m-EPR1 exhibit the trends of somewhat higher $\tau_{\mathrm{M}}$ values then with m-EPR2 (especially at $20 \mathrm{vol} . \%$ of added $\mathrm{m}$-EPR's) due to significantly higher viscosity of m-EPR1 than m- EPR2 copolymer (see MFI values in Table 1). Moreover, the $\tau_{\mathrm{M}}$ values of blends with

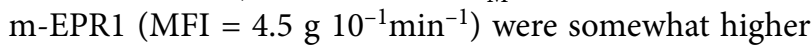

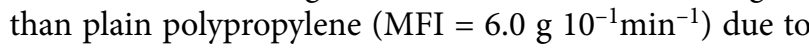
somewhat higher viscosity of $\mathrm{m}-\mathrm{EPR} 1$ than plain iPP. 


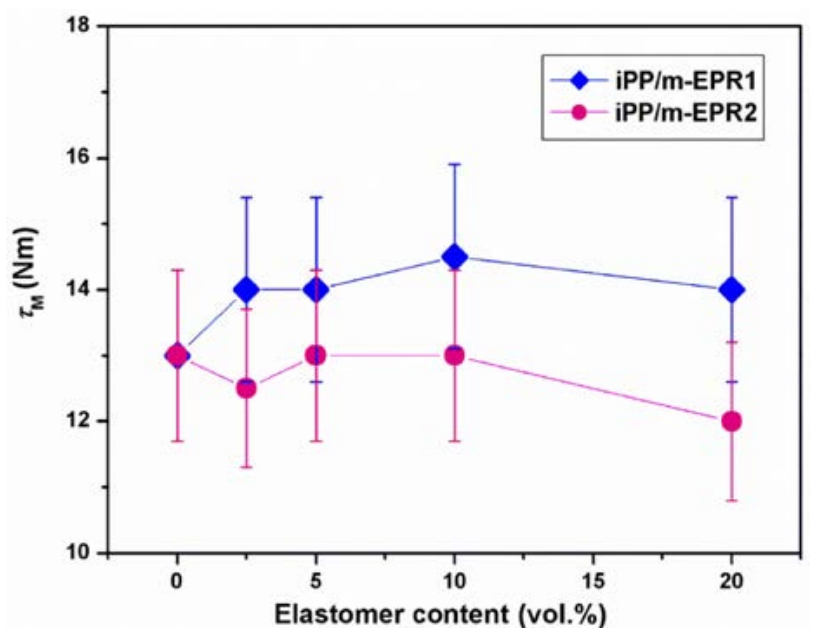

Figure 1. Steady state torque of the iPP/m-EPR blends in dependance on volume content of added elastomers

\section{2. Tensile Test}

\section{2. 1. Young's Modulus}

The addition of both $\mathrm{m}$-EPR elastomers to iPP matrix decreases Young's modulus steadily and almost linearly due to toughening effect of elastomers (Figure 2). ${ }^{7-9,23}$

An almost linear decrease of close $E$ values is in accordance with the parallel model with linear combination of plastic and elastomeric components. ${ }^{24}$ Although $\mathrm{m}$-EPR2 elastomer has significantly lower viscosity than

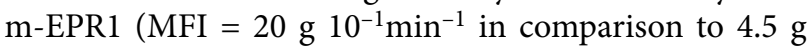
$10^{-1} \mathrm{~min}^{-1}$ for m-EPR1) due to lower molecular mass $\left(M_{\mathrm{n}}\right.$ $=48.100$ in comparison to $92.900 \mathrm{~g} \mathrm{~mol}^{-1}$ for $\mathrm{m}$-EPR 1 ) the blends with m-EPR2 exhibit just minor decline of the $E$ values than blends with $\mathrm{m}$-EPR1 elastomer.

For a further analysis of the $E$ data, the experimental values were compared with the values calculated by the different theoretical models based on the modulus-concentra-

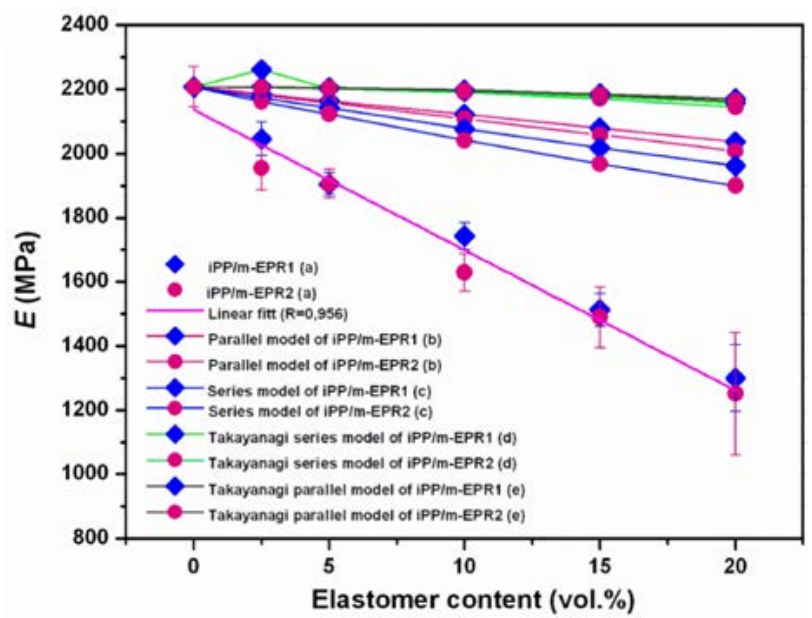

Figure 2. Young's modulus of the iPP/m-EPR blends as a function of the m-EPR content compared to the theoretical predictions: (a) experimental values, (b) parallel model, (c) series model, (d) Takayanagi parallel model, (e) Takayanagi series model tion dependence of two-phase polymeric materials. The elastic moduli of stiffness of a material is affected by the elastic moduli of all components, fraction of components, the morphology and the interactions between the components. The $E$ models usually presume the idealization about perfect adhesion between the phases, spherical particles and perfectly distributed minor phase through the matrix. ${ }^{25,26}$ The most simple of all models for predicting the moduli of a composite or a blend is known as the parallel model and has been considered as the upper limit of elastic modulus:

$$
E_{1,2}=E_{1} \varphi_{1}+E_{2} \varphi_{2}
$$

where the $E_{1,2}$ is the elastic modulus of compound, $E_{1}$ and $E_{2}$ are the elastic modulus of components. The series model represents the lower limit of elastic modulus:

$$
\frac{1}{E_{1,2}}=\frac{\varphi_{1}}{E_{1}}+\frac{\varphi_{2}}{E_{2}}
$$

Takayanagi developed a combined series-parallel model for the tensile property $E$, by introducing a degree of parallelinity into the series model. ${ }^{27,28}$ It was assumed that the two-phase material can be treated as a combination of series and parallel elements. The equation for Takayanagi parallel model is given as:

$$
E_{1,2}=\left[\frac{\varphi}{(1-\lambda) E_{1}+\lambda E_{2}}+\frac{1-\varphi}{E_{1}}\right]
$$

and for series model:

$$
E_{1,2}=\lambda\left[\frac{\varphi}{E_{2}}+\frac{1-\varphi}{E_{1}}\right]^{-1}+(1-\lambda) E_{1} .
$$

where the $E_{1}$ is the property of the matrix phase; $E_{2}$ is the property of the dispersed phase. Quantities $\lambda$ and $\varphi$ are geometry factors representing phase morphology in the Takayanagi model, whereas the product $\lambda \varphi$ is the volume fraction of the dispersed phase, and is related to the degree of series parallel coupling. Parameters $\lambda$ and $\varphi$ vary with composition and with the change in the state of dispersion. For spherical particles independently and homogeneously dispersed in a matrix, it can be assumed that $\lambda$ is equal to $\varphi .^{27,28}$ The Figure 2 showed that calculated models have higher values than measured experimental values for iPP/ m-EPR blends. Both Takayanagi's models showed almost the same behavior as classic series and parallel model in this case. The divergence can be related with partial miscibility of phases in blends (not only with interfacial adhesion), geometry and dispersion of added phase in polymer matrix and other factors. ${ }^{25-28}$ 


\section{2. 2. Yield stress and Strain (Tensile Strength and Elongation at Yield)}

Yield stress gives additional information on polymer matrix-elastomer interactions in binary blends besides how the elastomers affect yield stress as impact modifiers. ${ }^{2,3}$ Steady, monotonous decrease of $\sigma_{\mathrm{y}}$ values with addition of both, $\mathrm{m}$-EPR1 and m-EPR2 elastomers (Figure 3) indicates gradually increase of toughening similarly to gradually reduced stiffness (Figure 2) with increased elastomer content. Slightly higher $\sigma_{y}$ values of the $\mathrm{iPP} / \mathrm{m}-\mathrm{EPR} 2$ than $\mathrm{iPP} / \mathrm{m}-\mathrm{EPR} 1$ blends at higher elastomer contents might be ascribed to different factors and will be discussed at Tensile strength and elongation at break section.

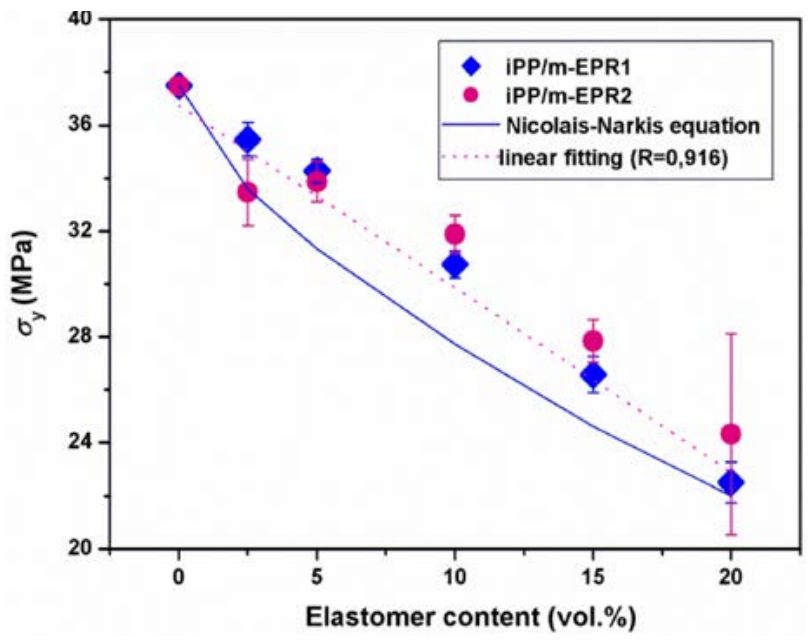

Figure 3. Tensile strength at yield of the iPP/m-EPR blends in dependence on volume content of added elastomers and Nicolais-Narkis model for yield strength

Nicolais and Narkis developed a model for yield strength of polymeric materials containing spherical particles for class of polymer systems based on the interphase properties. ${ }^{29}$ According to Nicolais-Narkis model, when interfacial adhesion does not exist between polymer and elastomer, the particles in matrix cannot bear the stress and it could be carried only through the matrix. Nevertheless, when a good interfacial adhesion is provided between matrix and dispersed phase the interfacial layer can transfer a fraction of stress from matrix to dispersed phase. So in this case the yield strength includes both matrix and dispersed phase contributions so the simplified equation can be expressed:

$$
\sigma_{b}=\sigma_{m}\left(1-1.21 \varphi_{f}^{2 / 3}\right)
$$

where $\sigma_{b}$ and $\sigma_{\mathrm{m}}$ are yield strength of blend and matrix and $\Phi_{\mathrm{f}}$ is the volume fraction of particles, assuming that dispersed particles in polymer matrix are spherical and there is a good adhesion. This model corresponds well to iPP/m-
EPR blends containing spherical particles of m-EPR with proved good adhesion, and exhibits somewhat lower values comparing to experimental values (Figure 3). ${ }^{30}$

The extent of yield strain, $\varepsilon_{y}$, of neat semicrystalline iPP primarily depends on the strengthening of tie molecules in amorphous interlayer (intercrystalline links) and interspherulitic links. Whereas the addition of m-EPR1 affects the elongation at yield negligibly, the addition of $\mathrm{m}$-EPR2 increases yield strain steadily (Figure 4 ). Stronger strengthening effect of $\mathrm{m}$-EPR2 than $\mathrm{m}$-EPR1 elastomer has been also observed at ternary $\mathrm{iPP} /$ silica/m-EPR and composites. ${ }^{31}$ It could be ascribed to better stress transfer from softer m-EPR2 particles as bumpers and better miscibility of m-EPR2 than m-EPR1 with iPP matrix, and might also lead to higher elongations with regard to stiffer m-EPR1 particles. However, more significant divergence in strain behavior in present case could be reasonable due to more effective stretching in simpler binary blend system (without filler).

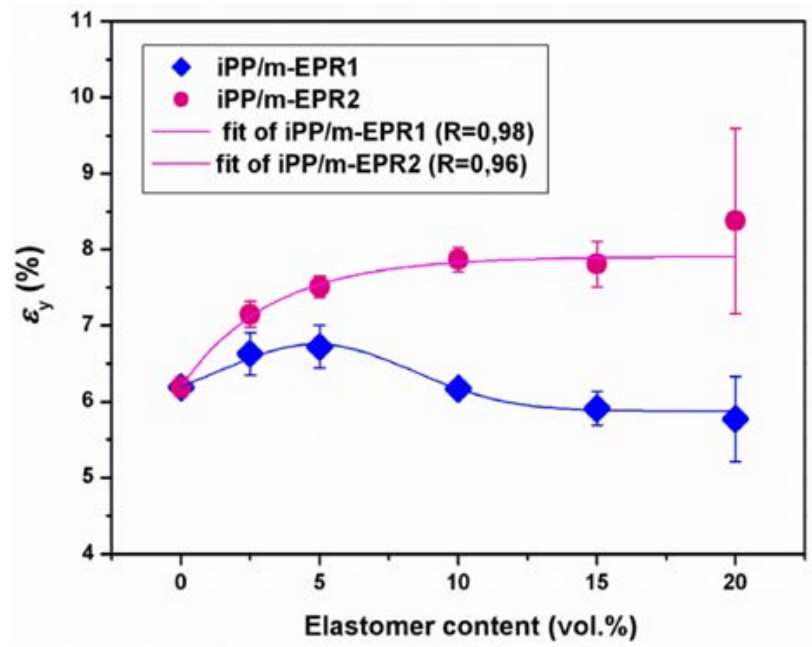

Figure 4. Elongation at yield of the $\mathrm{iPP} / \mathrm{m}-\mathrm{EPR}$ blends in dependence on volume content of added elastomers

\section{2. 3. Tensile Strength and Elongation at Break}

Although the incorporation of elastomeric modifiers into iPP matrix might have complex influence to the tensile strength at break, $\sigma_{\mathrm{b}}$ values of the iPP/m-EPR blends monotonously decrease with increased elastomer content (Figure 5) similarly to steady decrease of $E$ (Figure 2) and $\sigma_{\mathrm{y}}$ (Figure 3) values. Somewhat higher $\sigma_{\mathrm{y}}$ and $\sigma_{\mathrm{b}}$ values of the iPP/m-EPR2 than for iPP/m-EPR1 blends at higher m-EPR2 contents, has been primarily conducted (driven) by the difference in molecular weights of elastomers analogous to similar yield stress behavior.

Higher values of iPP/m-EPR2 might also be ascribed to higher crystallinity and spherulite size, compatibility or miscibility of the iPP/m-EPR2 than iPP/m-EPR1 blends and to stronger interfacial effect (interfacial free energy) at iPP-m-EPR2 interface. However, the effects of mentioned 
factors could not be resolved and ascribed to any of mentioned influencing factors due to slight difference in $\sigma_{\mathrm{y}}$ and $\sigma_{\mathrm{b}}$ values between these two m-EPR elastomers.

Higher viscosity $\mathrm{iPP} / \mathrm{m}-\mathrm{EPR} 2$ ratio than $\mathrm{iPP} / \mathrm{m}$ EPR1 (Figure 1) leads to smaller size of dispersed m-EPR2 than m-EPR1 particles. ${ }^{31}$ Moreover, prolonged crystallization of iPP matrix with additions of both m-EPR's was affected by migration of iPP chains from the remained melt islands of both elastomers, i.e. by solidification effect. ${ }^{31}$ However, higher partial miscibility of the iPP with m-EPR2 than $\mathrm{m}$-EPR1 (proved exactly by $\mathrm{DMA}^{31}$ ) as well as m-EPR2 with lower molecular mass and higher mobility of macromolecules than m-EPR1 macromolecules may more easily diffuse into the iPP interlamellar amorphous layer where they may form domains more or less interconnected with the amorphous iPP phase, thus increasing its thickness. ${ }^{16}$

This statement was proved by higher spherulite size of blends with m-EPR2 than m-EPR1 elastomer. ${ }^{31}$ Intraspherulitically accommodated smaller m-EPR's dispersed particles beside their interspherulitically accommodation may indicate better stress transfer from softer m-EPR2 particles as bumpers and might also lead to higher elongations additionally.

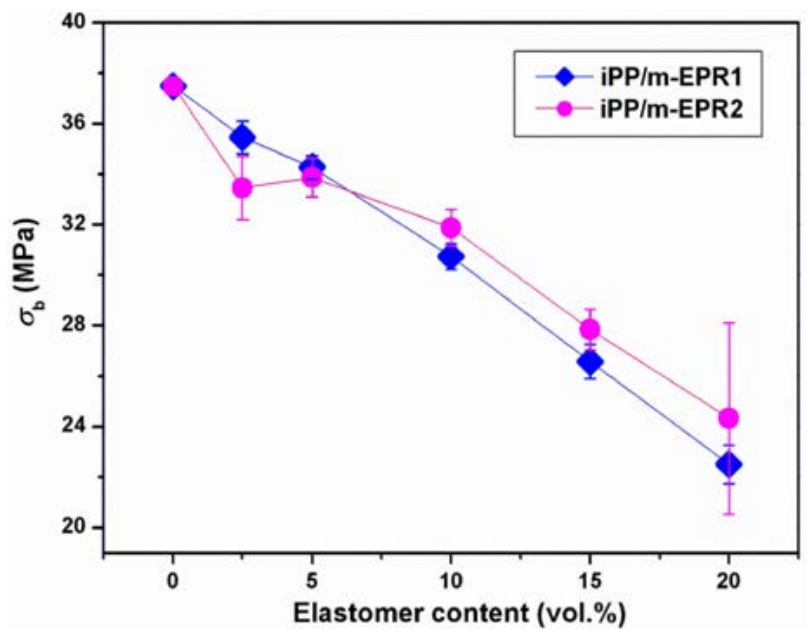

Figure 5. Tensile strength at break of the iPP/m-EPR blends in dependence on volume content of added elastomers

The elongation at break, $\varepsilon_{\mathrm{b}}$, usually behaves inversely to the tensile strength at break, $\sigma_{\mathrm{b}}$. Indeed, the $\varepsilon_{\mathrm{b}}$ values increases with increased $\mathrm{m}$-EPR 1 and $\mathrm{m}$-EPR2 content almost linearly after 2.5 vol.\% of elastomer (Figure 6 ). However, in distinct to $\sigma_{\mathrm{b}}$ values behavior, $\varepsilon_{\mathrm{b}}$ values of both blend systems are very close in whole concentration range. The elongation at break, $\varepsilon_{\mathrm{b}}$ after 5 vol.\% increases exceptionally fast with respect to pure isotactic polypropylene. The reason for such profound increase is probably the plasticization effect caused by addition of the m-EPR elastomer that has great impact on elongation properties of blends acting like plasticizers dissolved in the matrix phase

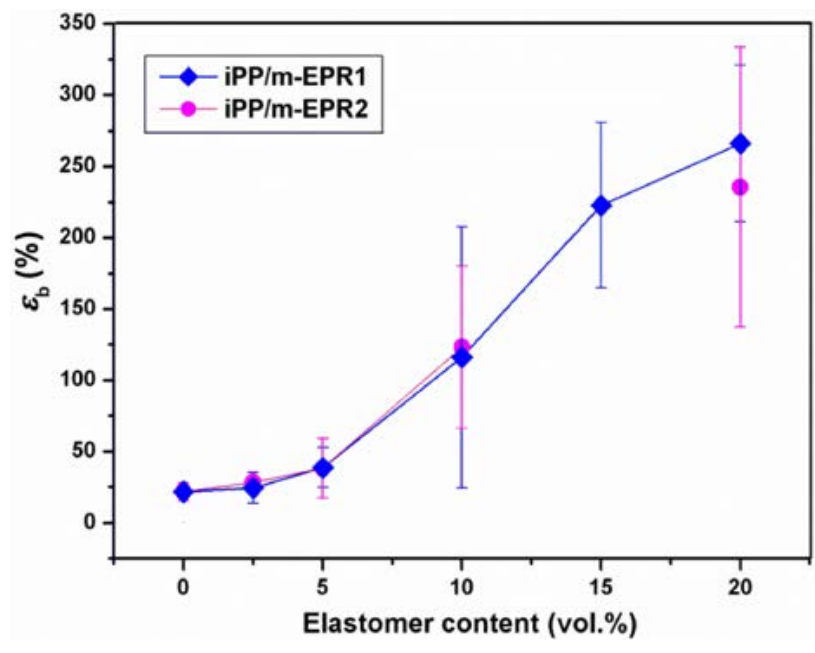

Figure 6. Elongation at break of the iPP/m-EPR blends in dependence on volume content of added elastomer

in large concentration range. The slopes of $\varepsilon_{b} \mathrm{iPP} / \mathrm{m}$-EPR for both added elastomers are very similar because of very similar structure of both elastomers.

\section{3. Impact Properties}

The incorporation of the m-EPR elastomers toughness plastomeric $\mathrm{iPP}$ matrix and increases impact strength, $a_{\mathrm{K}}$, values almost exponentially (Figure 7). The both $\mathrm{m}$ EPR's considerably improve $a_{\mathrm{K}}$ at additions higher than 10 vol.\% of m-EPR's analogously to similar behavior with addition of poly(styrene- $b$-ethylene-co-propylene) in iPP. ${ }^{28}$

These results proved that both $\mathrm{m}$-EPR's have efficient rubber-toughening characteristics for polypropylene. It is known that the phase separation is essential for producing impact-resistant blends for many polymeric systems. The $\mathrm{m}$-EPR elastomer dissolved in the matrix phase can act as a plasticizer, reducing the glass-transition temperature and stiffness of the matrix without increasing its toughness. ${ }^{32}$

However, other important facts influencing the impact strength of the iPP must be considered in addition to the afore mentioned facts: (non)existence of $\beta$-phase iPP, stiffness reduction, particle-matrix adhesion (or miscibility), etc. The iPP/m-EPR's blends exhibited mainly monoclinic $a$-form of the iPP in iPP/m-EPR blends, ${ }^{33}$ in distinct to the appearing of $\beta$-phase in iPP/SEP blends with poly(styrene- $b$-ethylene-co-propylene), ${ }^{28}$ with superior impact resistance to $\alpha$-phase iPP in present iPP/m-EPR blends. ${ }^{34}$ However, the toughness of the iPP/m-EPR blends is commensurable with the iPP/SEP blends. ${ }^{28}$ This fact indicates that new metallocene m-EPR copolymers exhibit higher toughening effect in comparison to SEP elastomer as custom SBC copolymer toughening agents. ${ }^{28}$ Altough the iP$\mathrm{P} / \mathrm{m}$-EPR2 blend exhibited doubtless higher degree of miscibility than iPP/m-EPR1 blends, ${ }^{33}$ higher $a_{\mathrm{K}}$ values of the iPP/m-EPR1 than for iPP/m-EPR2 blend could be observed in whole concentration range (Figure 7). This fact 
could be explained by almost twice higher molecular weight of $m$-EPR1 than m-EPR2, e.g. by MFI value of $\mathrm{m}$-EPR1 commensurable with the iPP (Table 1) that might affect impact strength in two ways. First, dispersed particles of copolymer with longer macromolecules exhibit higher toughness. Secondly, longer macromolecules or longer olefins segments similar to this one of the iPP chains may provide stronger mutual entanglements improving thus the notched impact strength (Figure 7). Similar difference in toughening effects of these two m-EPR's copolymers has been observed in composites of the iPP/ wollastonite and $\mathrm{iPP} /$ silica. $^{31,35}$

Obviously, the effect of macromolecular length prevails the effect of miscibility in toughening of $\mathrm{iPP} / \mathrm{m}$-EPR blends.

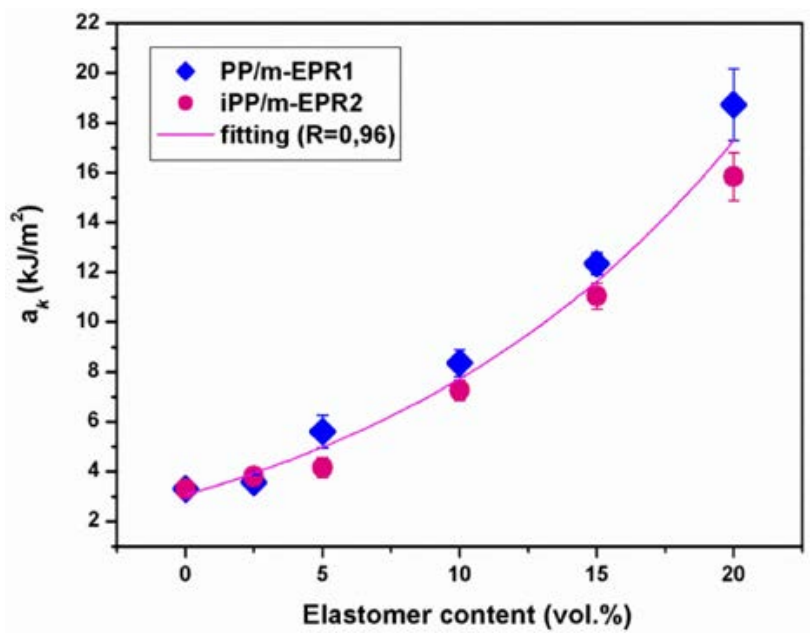

Figure 7. Notched impact strength of the iPP/m-EPR blends in dependence on volume content of added elastomers

\section{4. iPP Matrix-elastomer Interactions}

\section{4. 1. Parameter Interactivity $B$ of $i P P / m-E P R$ Blends}

The strength of polymer-elastomer interactions can be quantitatively described using Pukanszky's model for particle-based composites, as described in equation (10). ${ }^{36}$ More specifically, equation (10) allows to investigate a linear relationship existing between the natural logarithm:

$$
\ln \left(\frac{\sigma_{y c}}{\sigma_{y p}} \frac{1+2,5 \varphi_{d}}{1-\varphi_{d}}\right)=\ln \sigma_{y r e l}=B \varphi_{d}
$$

where $\sigma_{\mathrm{yc}}$ is the yield stress of elastomer and $\sigma_{\mathrm{yp}}$ is the yield stresses of matrix, respectively; $B$ is a term corresponding to the load carrying capability of the elastomer and depends on elastomer-matrix interactions; $\varphi_{\mathrm{d}}$ is the elastomer volumetric fraction within polymer matrix. If $\ln \left[\sigma_{\mathrm{yc}}(1\right.$ $\left.+2.5 \Phi_{\mathrm{f}}\right) /\left(\sigma_{\mathrm{yp}}\left(1-\Phi_{\mathrm{f}}\right)\right]$ of fraction value is plotted against of elastomer, parameter $B$ can be calculated as a line slope, with intercept in cross section of coordinate parameter

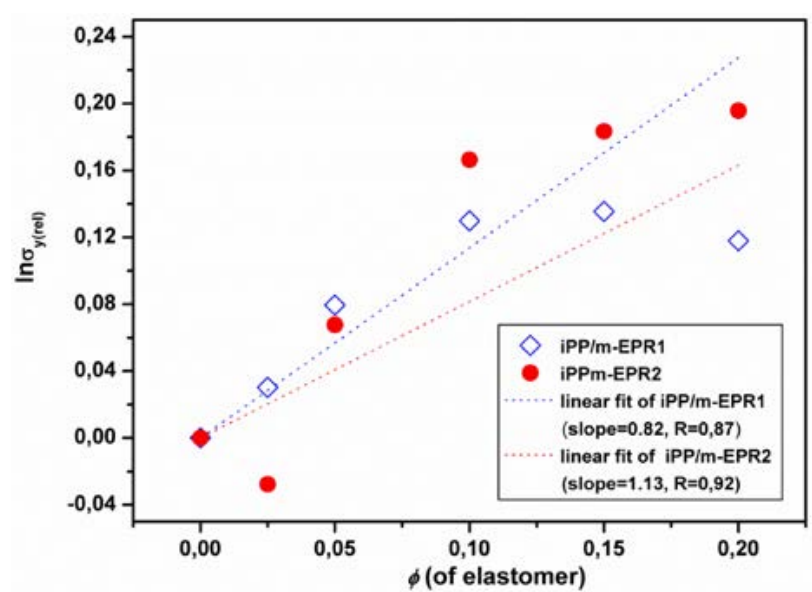

Figure 8. Presentation of calculated $\ln \sigma_{\text {rel }}$ values in dependence on elastomer content

Table 3. Interaction parameter $B$ for iPP/m-EPR blends

\begin{tabular}{cc}
\hline Blend iPP/m-EPR & Interaction parameter $\mathbf{B}$ \\
\hline $\mathrm{iPP} / \mathrm{mEPR}-1$ & 0.82 \\
$\mathrm{iPP} / \mathrm{mEPR}-2$ & 1.13 \\
\hline
\end{tabular}

axes. This assumes a tensile yield stress of matrix $\left(\sigma_{\mathrm{yp}}\right)$ to be constant.

Calculated $\ln \sigma_{\text {rel }}$ values were presented in Figure 8 in dependence on elastomer content and proportional to values of Pukanszky's ${ }^{36}$ interaction parameter showed in Table 3. Higher interaction parameter $\mathrm{B}$ value for $\mathrm{iPP} / \mathrm{m}$ EPR2 (1.13) than for $\mathrm{PPP} / \mathrm{m}$-EPR1 blend (0.82) corresponds to higher $\sigma_{\mathrm{y}}$ values for iPP/m-EPR2 blend. This fact corresponds well with proved higher miscibility of $\mathrm{iPP} / \mathrm{m}-\mathrm{EPR} 2$ than iPP/m-EPR1 blends. ${ }^{33}$

\section{4. 1. Adhesion Parameters of iPP/m-EPR Blends}

Interfacial properties may also affect the strength of polymer-elastomer interactions. The results of the studies on the effective adhesion for a given system indicate some conditions as optimal: thermodynamic work of adhesion as a maximal, spreading coefficient as a positive value and interfacial free energy as a minimal (tends to null) (Table 3). ${ }^{21,37,38}$ The surface free energy of the polypropylene and elastomers are showed in Table 4.

Table 4. The surface free energy $(\gamma)$ of the iPP and elastomers and their dispersive $\left(\gamma^{\mathrm{d}}\right)$ and polar component values $\left(\gamma^{\mathrm{p}}\right)$ evaluated by using the Wu's model ${ }^{21}$

\begin{tabular}{llcc}
\hline \multirow{2}{*}{ Polymer } & \multicolumn{3}{c}{ The surface free energies $\left(\mathbf{m J} / \mathbf{m}^{2}\right)$} \\
& $\boldsymbol{\gamma}^{\boldsymbol{d}}$ & $\boldsymbol{\gamma}^{\boldsymbol{p}}$ & $\boldsymbol{\gamma}$ \\
\hline iPP & 31.5 & 1.3 & 32.8 \\
mEPR-1 & 26.7 & 4.7 & 31.4 \\
mEPR-2 & 25.3 & 1.4 & 26.7 \\
\hline
\end{tabular}


Table 5. Adhesion parameters $\gamma_{\mathrm{AB}}, W_{\mathrm{AB}}, S_{\mathrm{AB}}$ of the iPP/m-EPR blends

\begin{tabular}{lccc}
\hline $\begin{array}{l}\text { Possible } \\
\text { adhesion pairs }\end{array}$ & $\begin{array}{c}\text { Adhesion parameters }\left(\mathbf{m} \mathbf{J} / \mathbf{m}^{2}\right) \\
\text { Wnterfacial free } \\
\text { energy } \gamma_{\mathbf{A B}}\end{array}$ & $\begin{array}{c}\text { Work of adhesion } \\
\mathbf{W}_{\mathbf{A B}}\end{array}$ & $\begin{array}{c}\text { Spreading } \\
\text { coefficient } \mathbf{S}_{\mathrm{AB}}\end{array}$ \\
\hline $\mathrm{iPP} / \mathrm{m}-\mathrm{EPR} 1$ & 2.32 & 62.9 & -2.7 \\
$\mathrm{iPP} / \mathrm{m}-\mathrm{EPR} 2$ & 0.78 & 59.2 & -6.4 \\
\hline
\end{tabular}

${ }^{*} \gamma_{\mathrm{mf}}$ for calculation according to Wu's equation

Higher interfacial free energy for EPR-1 than for EPR-2 were calculated with Wu's equation (1) (Table 4). The surface free energy for m-EPR1 elastomer is close to value for iPP. The ethylene-propylene copolymers $\mathrm{m}$-EPR1 and $\mathrm{m}$-EPR2 differed in polar component of surface free energy and the m-EPR1 is more polar than m-EPR2 and iPP with almost similar polarity.

Interfacial free energy, $\gamma_{\mathrm{AB}}$, work of adhesion, $W_{\mathrm{AB}}$, and spreading coefficient, $S_{\mathrm{AB}}$, of all polymer/elastomer pairs for the iPP/m-EPR blends were calculated according to equations (2-4) (Table 5).

However, higher interfacial free energy for iPP-mEPR1 $\left(\gamma=2.32 \mathrm{~mJ} / \mathrm{m}^{2}\right)$ than for iPP-m-EPR2 $(\gamma=0.78 \mathrm{~mJ} /$ $\mathrm{m}^{2}$ ) indicates contrary - stronger interfacial effect of the iPP-m-EPR2 than for iPP-m-EPR1 interface. In this case the interfacial free energy, as the inversely proportioned to the strength of intermolecular interactions in polymer blends, would be more relevant for such ambiguous systems. ${ }^{39,40,41}$ Higher interaction parameter B value for the $\mathrm{iPP} / \mathrm{m}$-EPR2 than for iPP/m-EPR1 blend seemed to confirm this ambiguous fact.

\section{5. Miscibility/Compatibility and Interactivity}

Better miscibility of the iPP/m-EPR2 than iPP/mEPR1 blend was confirmed with Dinamic Mechanical Analysis, DMA (one mutual intermediary maximum in E'/T curve of the iPP/m-EPR2 blend comparison to two overlapped $\beta$-relaxation maxima of the iPP/m-EPR1 blend) in our previous paper. ${ }^{33}$ The DMA results as well as biphasic morphology observed by all microscopy techniques suggests that $\mathrm{m}$-EPR2 molecules are not completely dissolved into the iPP amorphous region, i.e. partial miscibility and compatibility between $\mathrm{m}$-EPR2 particles and iPP matrix is better than with m-EPR $1 .{ }^{33}$ The higher crystallinity due to crystallization across phase boundary at dispersed $\mathrm{m}$-EPR2 particles and increased spherulite size in the iPP/m-EPR2 may affect the yield stress of semicrystalline polymers besides higher miscibility/ compatibility. ${ }^{42,43}$

The effect of spherulite size on yield stress depends on its position on summary curve tensile strength as a function of spherulite size related to the intraspherulite yield. ${ }^{31}$ Intraspherulitical location of both dispersed m-EPR particles in the iPP matrix had been observed by polarized optical micrographs ${ }^{31}$ interspherulitical accom- modation. Homogeneous distribution of dispersed $\mathrm{m}$-EPR1 particles (some in radial directions) in TEM micrograph of $\mathrm{iPP} / \mathrm{m}$-EPR1 80/20 blend in Figure 9 also indicates intraspherulitical location of m-EPR1 particles. ${ }^{33}$

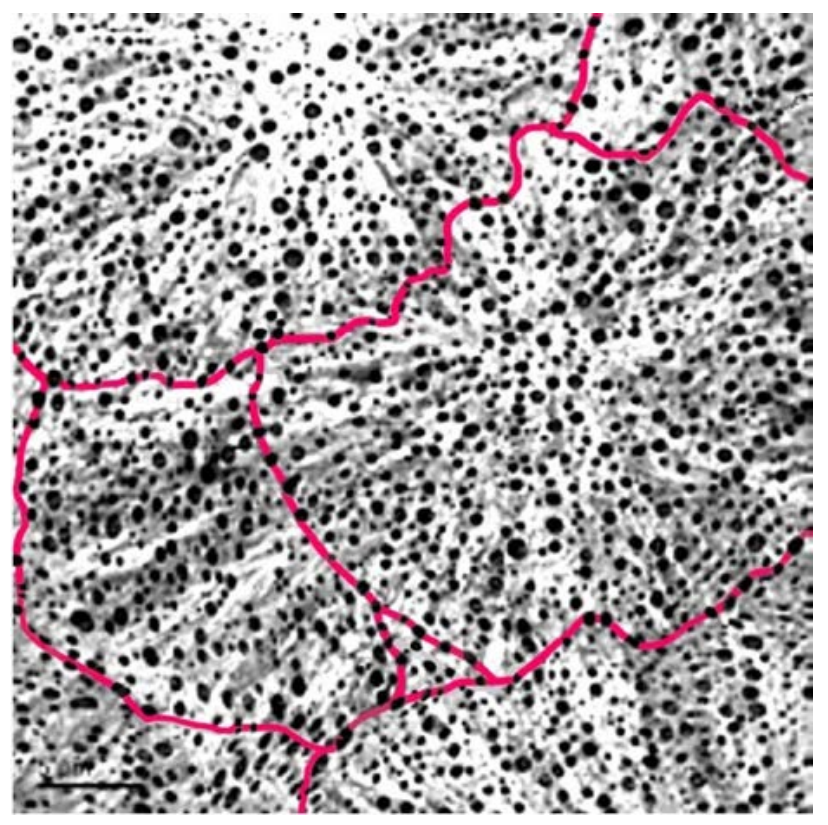

Figure 9. TEM picture of iPP/m-EPR1 80/20 with marked spherulites boundaries indicating intraspherulitical besides interspherulitical accommodation of m-EPR particles

The difference is only in somewhat thinner dispersed m-EPR2 (up to $1,2 \mu \mathrm{m}$ ) than m-EPR1 particles (up to 2.5 $\mu \mathrm{m})$ due to Jordhamo law. ${ }^{44}$ It is well known that dispersed particle size and distribution may affect yield properties. It was proved that the particle size of the elastomer significantly affects the deformation and failure processes in polypropylene toughened with olefinic elastomer being small particle favouring shear yielding while coarser dispersion promotes crazing due to difference in an average surface-to-surface interparticle distance. ${ }^{45,46,47}$

\section{6. Optimization Diagrams of Mechanical Properties of iPP/m-EPR Blends}

Mechanical properties are one of the most respected criteria for choosing right materials for some end-use pur- 
pose. Schematic diagrams show the change in some important materials' mechanical properties by introducing one or two components in polymer matrix. The optimization diagrams of such designed materials were used for comparing their mechanical parameters with the pure isotactic polypropylene.

The addition of propylene-ethylene elastomers in isotactic polypropylene decreased the Young's modulus as expected due to toughening effect of elastomers. The yield strength and strength at break also decrease by addition of elastomers and the values are higher for the blends with m-EPR2 elastomer with smaller molecular mass. The few times bigger increase in impact strength in comparison to iPP is the result of addition of soft elastomers in large concentration so the role of impact modifier is completely fulfilled. Higher $a_{\mathrm{K}}$ values of the iPP/m-EPR1 than for iPP/ $m$-EPR2 blend could be explained by almost twice higher molecular weight (longer macromolecules) of m-EPR1 than m-EPR2. Optimization diagram (Figure 10) indicate good balancing of mechanical properties besides efficient effect of metallocene m-EPR copolymers as impact modifiers for polypropylene.

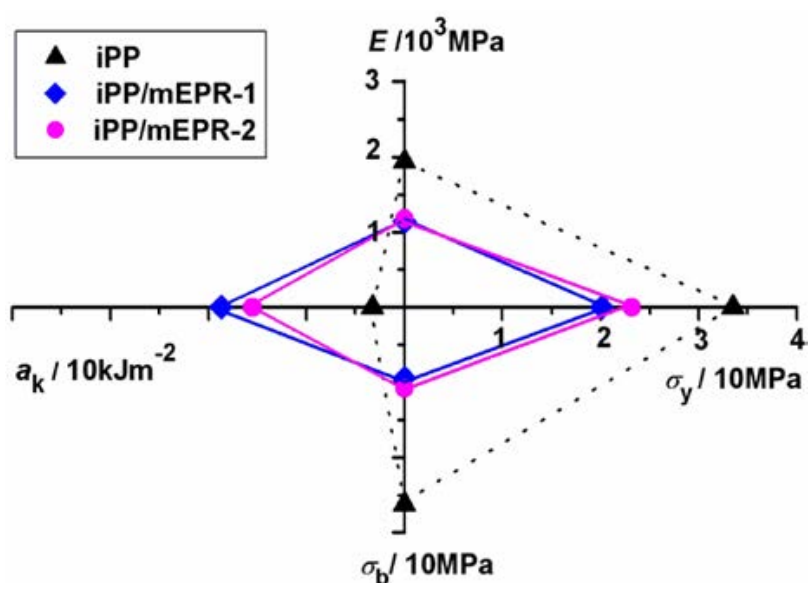

Figure 10. Optimization diagram of mechanical properties of iPP/ m-EPR blends with 20 vol. $\%$ of added elastomers

\section{Conclusions}

The effects of two metallocene ethylene-propylene-based elastomers with varied contents (2,5-20 vol.\% of $\mathrm{m}$-EPR1 and $\mathrm{m}$-EPR2) differing in molecular mass (viscosity) on mechanical, rheological and interfacial properties of the iPP/m-EPR blends were investigated. While Young's modulus, tensile strength and yield and break of the iPP/m-EPR's blends decreased, impact strength and elongation at break increased with increased elastomer content. Such behavior of presented iPP/m-EPR blends resulted primarily by prevailed toughening or plastification effect caused by spherically shaped dispersed m-EPR particles. Thereby, elongation at break and impact strength as well as torque values of the iPP/m-EPR1 blends were higher of the iPP/m-EPR2 blends due to higher molecular mass, e.g. higher molten viscosity of $m$-EPR1 than m-EPR2 copolymer. However, slight divergence of almost linearly decreased $E, \sigma_{\mathrm{y}}$ and $\sigma_{\mathrm{b}}$ values of the iPP/m-EPR's blends could be ascribed to different factors (difference in crystallinity and spherulite size, compatibility or miscibility of the iPP with m-EPR's, and interfacial effect at iPP-m-EPR interface) which could not be resolved. So the behavior of these values could not be ascribed to any of mentioned influencing factors particularly; it could be only concluded that the difference in viscosity or molecular length between two m-EPR's does not affect $E, \sigma_{\mathrm{y}}$ and $\sigma_{\mathrm{b}}$ values. Somewhat divergence of yield strain values resembles to similar divergence of torque values but in inverse mode. Whereas this divergence in torque values was governed by difference in molten viscosity of copolymers, the divergence of $\varepsilon_{y}$ values was governed by difference in miscibility of m-EPR's with iPP matrix and by difference in stress transfer from $\mathrm{m}$-EPR particles differently soft. Moreover, optimization diagrams indicated beside efficient effect of metallocene m-EPR copolymers as impact modifiers for polypropylene also its balancing effect of mechanical properties.

\section{Acknowledgements}

Financial support of the Ministry of Science, Education and Sports of the Republic of Croatia and the Ministry of Higher Education, Science and Technology of the Republic of Slovenia is acknowledged.

\section{References}

1. H. G. Karian, in: H. G. Karian (Ed.): Handbook of polypropylene and polypropylene composites, Marcel Dekker, New York, USA, 2003. DOI:0.1201/9780203911808

2. G. Wypych, in: G. Wypych (Ed.): Handbook of fillers, ChemTec Publishing, Toronto, Canada, 2000.

3. R. N. Rothon, in: R. N. Rothon (Ed.): Particulate-Filled Polymer Composites, Smithers Rapra Press, Shawbury, UK, 2006.

4. J. Karger-Kocsis, S. Fakirov, in: J. Karger-Kocsis, S. Fakirov (Eds.): Nano- and micromechanics of polymer blends and composites, Carl Hanser Verlag, Munich, Germany, 2010.

5. R. N. Rothon, in: M. Xanthos (Ed.): Functional Fillers for Plastics, Wiley-VCH Verlag, Weinheim, Germany, 2010.

6. X. Chen, G. Ma, J. Li, S. Jiang, X. Yuan, J. Sheng, Polym. 2009, 50, 3347-3360. DOI:10.1016/j.polymer.2009.04.069

7. D. N. Bikiaris, G. Z. Papageorgiou, E. Pavlidou, N. Vouroutzis, P. Palatzoglou, G.P. Karayannidis, J. Appl. Polym. Sci. 2006, 100, 2684-2696. DOI:10.1002/app.22849

8. M. Z. Rong, M. Q. Zhang, Y. X. Zheng, H. M. Zeng, R. Walter, K. Friedrich, Polym. 2001, 42, 167-183.

DOI:10.1016/S0032-3861(00)00325-6 
9. C. L. Wu, M. Q. Zhang, M. Z. Rong, K. Friedrich, Compos. Sci. Technol. 2002, 62, 1327-1340. DOI:10.1016/S0266-3538(02)00079-9

10. T. H. Zhou, W. H. Ruan, Y. L. Mai, M. Z. Rong, M. Q. Zhang, Compos. Sci. Technol. 2008, 68, 2858-3066. DOI:10.1016/j.compscitech.2007.10.002

11. A. Vassiliou, D. N. Bikiaris, E. Pavlidou, Macromol. React. Eng. 2007, 1, 488-501. DOI:10.1002/mren.200700006

12. Y.-Q. Zhang, Z.-Q. Fan, L.-X. Feng, J. Appl. Polym. Sci. 2002, 84, 445-453. DOI:10.1002/app.10415

13. K. Nitta, A. Tanaka, Polym. 2001, 42, 1219-1226. DOI:10.1016/S0032-3861(00)00418-3

14. C. Grein, K. Bernreitner, M. Gahleitner, J. Appl.Polym. Sci. 2003, 87, 1702-1712. DOI:10.1002/app.11696

15. L. D’Orazio, G. Cecchin, Polym. 2001, 42, 2675-2684. DOI:10.1016/S0032-3861(00)00631-5

16. L. D’Orazio, C. Mancarella, E. Martuscelli, G. Sticotti, G. Cecchin, J. Appl.Polym. Sci. 1999, 72, 701-719. DOI:10.1002/(SICI)1097-4628(19990502)72:5<701: :AID-APP11>3.0.CO;2-U

17. C. Grein, M. Gahleitner, Express. Polym. Lett. 2008, 2, 392397. DOI:10.3144/expresspolymlett.2008.47

18. K. Trongtorsak, P. Supaphol, S. Tantayanon, Polym.Test. 2004, 23, 533-539.

DOI:10.1016/j.polymertesting.2003.11.006

19. The use of Vistamaxx ${ }^{\mathrm{TM}}$ specialty elastomers in Thermoplastic Compounds \& Blends, http://www.baixii.com/upload/ files/2015/3/2621142284.pdf (accesed March 30, 2017).

20. S. Datta, S. Srinivas, G. Racine, in: Novel Propylene-Based Specialty Elastomers- Structure and Properties, ANTEC $62^{\text {nd }}$ annual technical conference, Chicago, USA, 2004, p. 422.

21. S. Wu, J. Adhes. 1973, 5, 39-55.

22. H. N. Hemmati, H. Nazokdast, H. S. J. Panahi, J Appl .Polym. Sci. 2001, 82, 1129-1137. DOI:10.1002/app.1947

23. A. Pustak, M. Leskovac, M. Denac, I. Švab, J. Pohleven, M. Makarovič, V. Musil, I. Šmit, J. Reinf. Plast. Compos. 2014, 33, 851-861. DOI:10.1177/0731684413518827

24. U. W. Gedde, in: Polymer Physics, Springer Science+Business Media, Dordrecht, Netherlands, 1995.

25. M. Haghighat, A. Zadhoush, S. Nouri Khorasani, J. Appl. Polym. Sci. 2005, 96, 2203-2211. DOI:10.1002/app.21691

26. H. W. Zhang, J. B. Wang, X. Guo, J. Mech. Phys. Solids 2005, 53, 1929-1950. DOI:10.1016/j.jmps.2005.05.001

27. J. A. Gopi, G. B. Nando, Adv. Polym. Sci. Techn. 2014, 4, 43- 51.

28. G. Radonjič, I. Šmit, J. Polym. Sci. B. Polym. Phys. 2001, 39,
566-580. DOI:10.1002/1099-0488(20010301)39:5<566: :AID-POLB1030>3.0.CO;2-P

29. L. Nicolais, M. Narkis, Polym. Eng. Sci. 1971, 11, 194-199.

30. Y. Zare, Int. J. Adhes. Adhes. 2016, 70, 191-195.

31. A. Pustak, M. Denac, A. Sever Škapin, I. Švab, V. Musil, I. Šmit, J. Polym. Res. 2016, 23, 163 (1-13).

32. C. B. Bucknall, in: S. G. Aggarwal (Ed.): Comprehensive Polymer Science: The Synthesis, Characterization, Reactions and Applications of Polymers, Pergamon, Oxford, UK, 1989, pp. 27-34. DOI:10.1016/B978-0-08-096701-1.00205-6

33. A. Pustak, I. Švab, E. Govorčin Bajsić, M. Denac, V. Musil, I. Šmit, Polym. Plast. Technol. Eng. 2017, 57(3), 229-241.

DOI:10.1080/03602559.2017.1320720

34. M. Fujiyama, Int. Polym. Proc. 1998, 4, 411-416. DOI:10.3139/217.980411

35. I. Švab, V. Musil, A. Pustak, I. Šmit, Polym. Compos. 2009, 30, 1091-1097. DOI:10.1002/pc.20660

36. B. Pukanszky, Eur. Polym. J. 2005, 41, 645-662. DOI:10.1016/j.eurpolymj.2004.10.035

37. V. Mittal, in: V. Mittal (Ed.): Polymer Nanotube Nanocomposites: Synthesis, Properties, and Applications, Wiley\&Sons, Inc. Hoboken, New Jersey \& Scrivener Publishing LLC, Salem, Massachusetts, USA, 2010, pp. 449-460.

38. S. Steinmann, W. Gronski, C. Friedrich, Polymer. 2002, 43, 4467-4477. DOI:10.1016/S0032-3861(02)00271-9

39. G. Guerrica-Echevarria, J. I. Eguizabal, J. Nazabal Polym. Test. 2000, 19, 849-854. DOI:10.1016/S0142-9418(99)00055-0

40. G. Biresaw, C. J. Carriere, Compos. Part. A, 2004, 35, 313-320. DOI:10.1016/j.compositesa.2003.09.020

41. H. Liang, R. Xu, B.D. Favis, H.P. Schreiber, Polymer 1999, 40, 4419-4423. DOI:10.1016/S0032-3861(98)00767-8

42. M. Jenkins, N. J. Mills, in: Plastics: Microstructure and Engineering Applications, $3^{\text {rd }}$ edition, Butterworth-Heinemann for Elsevier, Oxford, UK, 1993, pp. 229-249.

43. A. K. Ghosal, Crystallization of Isotactic Poly(Propylenes) with Enachanted Melt Strength, Ph. D. Thesis, Florida State University, USA, 2008.

44. G. M. Jordhamo, J. A. Manson, L. H. Sperling, Polym. Eng. Sci. 1986, 26, 517-524. DOI:10.1002/pen.760260802

45. C. Lotti, C. A. Correa, S. V. Canevarolo, Mat. Res. 2000, 3, 37-44. DOI:10.1590/S1516-14392000000200007

46. C. J. Chou, K. Vijayan, D. Kirby, A. Hiltner, E. Baer, J. Mater. Sci. 1988, 23, 2521-2532. DOI:10.1007/BF01111912

47. J. A. W. van Dommelen, W. A. M. Brekelmans, F. P. T. Baaijens, Mech. Mater. 2003, 35, 845-863.

DOI:10.1016/S0167-6636(02)00307-1

\section{Povzetek}

$\mathrm{V}$ delu smo preučevali vpliv dveh metalocenskih elastomerov na osnovi etilena/propilena ( $\mathrm{m}-\mathrm{EPR} 1 \mathrm{in} \mathrm{m}-\mathrm{EPR} 2)$, ki sta se razlikovala v molekulski masi in viskoznosti, na mehanske, reološke in medpovršinske lastnosti. V iPP matrico smo dodali 2.5, 5, 10, 15 in 20 vol.\% m-EPR elastomera. Ugotovili smo, da imajo mešanice iPP/m-EPR1 višje vrednosti torzijskega momenta mešanja, raztezka ob pretrgu in udarne žilavosti kot mešanice iPP/m-EPR2 zaradi višje viskoznosti taline $\mathrm{m}$-EPR1 kot m-EPR2 elastomera. Manjše razlike $\mathrm{v}$ Youngovem modulu, meji plastičnosti in natezni trdnosti pri pretrgu kažejo, da natezne lastnosti mešanic iPP/m-EPR niso v veliki meri odvisne od viskoznosti ali molekulske mase, mešljivosti in velikosti sferolitov. Optimizirani diagrami kažejo, da so m-EPR elastomeri učinkoviti modifikatorji žilavosti za polipropilen in kažejo ugodno ravnotežje mehanskih lastnosti mešanic iPP/m-EPR. 